\title{
A Kinetic-Thermodynamic Study of the Effect of the Cultivar/Total Phenols on the Oxidative Stability of Olive Oils
}

\author{
Ana C.A. Veloso ${ }^{1,2} \cdot$ Nuno Rodrigues $^{3} \cdot$ Yosra Ouarouer $^{3,4} \cdot$ Khalil Zaghdoudi $^{4} \cdot$ José A. Pereira $^{3}$ (D) \\ António M. Peres ${ }^{3}$ (i)
}

Received: 2 October 2019 / Revised: 18 February 2020 / Accepted: 19 February 2020

(C) 2020 AOCS

\begin{abstract}
Physicochemical parameters, total phenols contents (TPC), and oxidative stabilities at $120-160{ }^{\circ} \mathrm{C}$ were evaluated for two monovarietal (Arbequina and Cobrançosa cultivars, $c v s$.) and one blend extra-virgin olive oil, confirming the label quality grade and allowing grouping them according to the different TPC (TPC $=88 \pm 7,112 \pm 6$ and $144 \pm 4 \mathrm{mg} \mathrm{CAE} / \mathrm{kg}$, for $c v$. Arbequina, blend and $c v$. Cobrançosa oils, respectively). The lipid oxidation rate increased with the decrease of the TPC, being Cobrançosa oils (higher TPC) more thermally stable. Kinetic-thermodynamic parameters were determined using the activated complex/transition-state theory and the values did not significantly differ for Cobrançosa and blend oils, which had the highest TPC, suggesting a hypothetically threshold saturation of the beneficial effect. Cobrançosa oils had a significant more negative temperature coefficient, higher temperature acceleration factor, greater activation energy and frequency factor, higher positive enthalpy of activation, lower negative entropy of activation, and greater positive Gibbs free energy of activation, probably due to the higher TPC. The results confirmed that lipid oxidation was a nonspontaneous, endothermic, and endergonic process with activated formed complexes
\end{abstract}

António M. Peres

peres@ipb.pt

1 Instituto Politécnico de Coimbra, ISEC, DEQB, Rua Pedro Nunes, Quinta da Nora, 3030-199, Coimbra, Portugal

2 CEB - Centre of Biological Engineering, University of Minho, Campus de Gualtar, 4710-057, Braga, Portugal

3 Centro de Investigação de Montanha (CIMO), ESA, Instituto Politécnico de Bragança, Campus Santa Apolónia, 5300-253, Bragança, Portugal

4 Département Génie Chimique, Université Libre de Tunis, Avenue Khéreddine-Pacha Tunis, 30, 1002, Tunis, Tunisia structurally more ordered than the reactants. A negative deviation from the Arrhenius behavior was observed for all oils being the super-Arrhenius behavior more marked for Arbequina oils that had the lowest TPC. Finally, the kineticthermodynamic parameters allowed classifying oils according to the binomial olive cultivar/total phenols level, being the temperature acceleration factor and the Gibbs free energy of activation at $160{ }^{\circ} \mathrm{C}$ the most powerful discriminating parameters.

Keywords Rancimat test - Monovarietal-blend oils thermal stability $\cdot$ Energy of activation $\cdot$ Enthalpy of activation - Entropy of activation · Free Gibbs energy

J Am Oil Chem Soc (2020) 97: 625-636.

\section{Introduction}

Olive oils and other vegetable oils suffer lipid oxidation, which is responsible for the oil chemical and sensory quality deterioration during storage, influencing the product shelf life and so, being a major concern for oil producers and consumers (Farhoosh et al., 2008). Lipid oxidation progress over time may be evaluated by monitoring primary, secondary, or tertiary oxidation products, although some of them may have a transient existence turning out their assessment a hard or even impossible task (Farhoosh and Hoseini-Yazdi, 2014). For example, peroxide value (PV), is a measure of the oils' hydroperoxides content, a primary product of the lipid oxidation, which is widely used to follow the pattern of the oils' oxidative deterioration. The oxidative stability (OS) of the oils, a measure of the volatile organic acids produced during the formation of the 
hydroperoxides or as a result of the oxidation of carbonyl compounds and other secondary (e.g., alcohols) or tertiary oxidation products may be used for monitoring the lipid oxidation progress (Farhoosh and Hoseini-Yazdi, 2014). The OS of olive and other vegetable oils (e.g., linseed, rapeseed, camelina, black cumin, evening primrose, hempseed, milk thistle, poppy, pumpkin, sunflower, cottonseed, hazelnut, sesame, among other oils) has been determined mainly using Rancimat test (Aktar and Adal, 2019; Ciemniewska-Żytkiewicz et al., 2014; Elhussein et al., 2018; Farhoosh et al., 2008; Gharby et al., 2016; Gülmez and Şahin, 2019; Hasenhuettl and Wan, 1992; Kowalski et al., 2004; Kurtulbaş et al., 2018; Mateos et al., 2006; Morsy et al., 2019; Mousavi and Niazmand, 2017; Ostrowska-Ligeza et al., 2010; Ratusz et al., 2016; Symoniuk et al., 2016, 2017, 2018; Yang et al., 2018). Other techniques have also been reported, namely, the differential scanning calorimetry (Ciemniewska-Żytkiewicz et al., 2014; Kowalski et al., 2004; Malvis et al., 2019; Ostrowska-Ligeza et al., 2010; Ratusz et al., 2016; Symoniuk et al., 2016, 2017, 2018) or the time-domain reflectometry (Sonkamble et al., 2017). Besides the OS data, the knowledge of kinetic and thermodynamic characteristics of lipid oxidation may contribute to a better understanding of the lipid oxidation underlying mechanisms allowing adjusting the composition of oils aiming the increase of the shelf life and minimizing the appearance of undesirable deterioration products. The literature data pointed out that the OS of olive oils as well as the related kinetic and thermodynamic parameters are highly influenced by the olive cultivar, the quality grade of the olive oil, the fatty acids composition, the phenols contents, or the composition in other bioactive compounds (Farhoosh et al., 2008; Gharby et al., 2016; Kowalski et al., 2004; Mahdavianmehr et al., 2016; Mateos et al., 2006). Within the bioactive compounds, phenolic compounds, which are normally related to the OS of the oils playing a key role in the increase of the oils' shelf life, clearly stand out (Boskou et al., 2006). Other properties are attributed to these compounds, enhancing their relevance, namely, in terms of sensory aspects and biological properties, as they are partly responsible for the health benefits associated to the olive oil consumption as an essential ingredient of the Mediterranean diet (Cicerale et al., 2010; Esposto et al., 2015). It should be noticed that the chemical compositions of olive oils have been widely studied showing that the levels are highly influenced by several factors including, olive cultivar, geographical origin, agro-climatic conditions, crop year, and olive maturation index at harvest, among other factors. In which concerns cultivars (cvs.) Cobrançosa or Arbequina oils (Portuguese and Spanish cultivars), similar overall fatty acid contents have been found, namely, high percentages of monounsaturated fatty acids (MUFA: $72-75 \%$ and $66-81 \%$, respectively), followed by saturated (SFA: 14-19\% and 12-22\%, respectively) and polyunsaturated fatty acids (PUFA: $8-11 \%$ and $7-15 \%$, respectively), being oleic acid (18:1) and palmitic acid (16:0) the most abundant ones for both oils (Borges et al., 2017a; Casal et al., 2010; Neves et al., 2011; Peres et al., 2016a, b; Sousa et al., 2015). Regarding the TPC, the literature values showed a huge variability, ranging from 60 to $350 \mathrm{mg} \mathrm{CAE} / \mathrm{kg}$ for $c v$. Cobrançosa oils (Casal et al., 2010; Sousa et al., 2015) and from 75 to $300 \mathrm{mg} \mathrm{CAE} / \mathrm{kg}$ for $c v$. Arbequina oils (Borges et al., 2017b, 2019), being hydroxytyrosol and tyrosol the most abundant phenolic compounds.

Thus, in this study it was intended to evaluate the influence of the total phenols content (TPC) on the lipid oxidation of two monovarietal olive oils (cvs. Arbequina and Cobrançosa) and one blend olive oil using a kineticthermodynamic approach based on the OS data determined using the Rancimat test at five different temperatures within the range of $120-160{ }^{\circ} \mathrm{C}$. Therefore, a series of kinetic and thermodynamic parameters were calculated, including the temperature coefficient $\left(T_{\mathrm{C}}\right)$ and temperature acceleration factor $\left(Q_{10}\right)$, the Arrhenius parameters (energy of activation, $E_{\mathrm{a}}$, and the frequency factor, $A$ ), the enthalpy, entropy, and Gibbs free energy of activation $\left(\Delta \mathrm{H}^{++}, \Delta \mathrm{S}^{++}\right.$, and $\Delta \mathrm{G}^{++}$, respectively). The gathered data would allow inferring about the effect of the TPC increase on the olive oil thermal stability, statistically assessed using the one-way ANOVA, as well as to establish the kinetic-thermodynamic characteristics of the lipid oxidation process, which for the first time carried out for oils produced from Portuguese olive cultivars, namely from $c v$. Cobrançosa. Finally, the possibility of using the kinetic and/or thermodynamic parameters as putative olive oil discrimination fingerprints regarding the binomial olive cultivar/TPC was explored for the first time. For this purpose, unsupervised and supervised multivariate pattern recognition statistical tools were applied, namely, principal component analysis (PCA) and linear discriminant analysis (LDA) coupled with the meta-heuristic simulated annealing (SA) variable selection algorithm. Indeed, as recently shown by Heidarpour and Farhoosh (2018), kinetic parameters like the frequency factor and the activation energy, could be successfully employed to establish, for example, an adulteration index that allowed revealing monovarietal olive oil adulterations with palm olein and sunflower oil.

\section{Materials and Methods}

\section{Olive Oil Samples}

The olive oil samples evaluated in this study were produced in 2018 crop season at a local olive mill (Olimontes, 
Macedo de Cavaleiros, Northeast Portugal), using a twophase centrifugation system. Olive oils were collected and assembled into three groups according to olive cultivar information provided by the oil producer ( $c v$. Arbequina, $c v$. Cobrançosa and a mix of cultivars) and a preliminary bitter-pungent intensity evaluation (data not shown), which theoretically, may be related to the TPC:

- $c v$. Arbequina oils with a low bitter-pungent sensation, which were expected to have low TPC;

- blend oils with a moderate bitter-pungent sensation, which were expected to have medium TPC; and,

- $c v$. Cobrançosa oils with an intense bitter-pungent sensation, which were expected to have high TPC.

The olive oils were kept in their original bottles, in a dark environment, at room temperature $\left(18-25{ }^{\circ} \mathrm{C}\right)$, being filtrated before analysis. Moreover, according to the producer information, all olive oils could be classified as extravirgin olive oils (EVOO).

\section{Evaluation of Olive Oils Quality Chemical Indices, TPC, and Oxidative Stabilities at Different Temperatures}

The values of the free acidity (FA), the extinction coefficients at 232 and $268 \mathrm{~nm}\left(\mathrm{~K}_{232}\right.$ and $\left.\mathrm{K}_{268}\right)$, and the peroxide value (PV) of the each of the five independent samples of each olive oil initial group ( $c v$. Arbequina, blend and $c v$. Cobrançosa oils with low, moderate and intense bitterpungent sensations, respectively) were determined following the standard methodologies described in the EC regulation (Commission Delegated Regulation [EU] 2015/1830, 2015), aiming to establish the olive oil commercial grade (EVOO, VOO, or LOO). In order to relate the bitterpungent intensity sensation (and olive cultivars) of the studied olive oils with the expected TPC, these were assessed and expressed as mg of caffeic acid equivalents per $\mathrm{kg}$ of olive oil (mg CAE $/ \mathrm{kg}$ ), using the methodology described by Capannesi et al. (2000) with some modifications as described by Rodrigues et al. (2018). Finally, the oxidative stabilities of the oils (OS) at different temperatures $\left(120,130,140,150\right.$ and $\left.160{ }^{\circ} \mathrm{C}\right)$ were assessed using the Rancimat method (Rancimat 743 apparatus from Metrohm $\mathrm{CH}$, Switzerland) following the methodology previous described (Rodrigues et al., 2016). This latter experimental information further allowed calculating kinetic data, enabling a thermodynamic characterization of the olive oils oxidative stability and its possible relation with TPC.

\section{Kinetic-Thermodynamic Parameters}

Kinetic-thermodynamic data can be determined using the OS experimental data recorded at different temperatures, using the Rancimat method as previously described in the literature (Ciemniewska-Żytkiewicz et al., 2014; Farhoosh et al., 2008; Farhoosh and Hoseini-Yazdi, 2014; Heidarpour and Farhoosh, 2018; Mahdavianmehr et al., 2016; Malvis et al., 2019; Trapani et al., 2017).

The temperature coefficient, $T_{\mathrm{C}}\left({ }^{\circ} \mathrm{C}^{-1}\right)$, is the slope value of the linear regression established between the decimal logarithmic of the OS, $\log _{10}(O S$, hours $)$, and the temperature $T\left({ }^{\circ} \mathrm{C}\right)$, at which the OS was determined, as described by Eq. 1:

$\log _{10}($ OS, hours $)=$ slope $_{I} \times T\left({ }^{\circ} \mathrm{C}\right)+$ intercept $_{I}$

$T_{\mathrm{C}}\left({ }^{\circ} \mathrm{C}^{-1}\right)=$ slope $_{I}$

The temperature acceleration factor, the $Q_{10}$ number, which is a measure of the increase in the reaction rate due to a $10{ }^{\circ} \mathrm{C}$ rise, can be then calculated using Eq. 3:

$Q_{10}=10^{-10 \times T_{\mathrm{C}}\left({ }^{\circ} \mathrm{C}^{-1}\right)}$

The frequency factor, $A$ (hours $^{-1}$ ) and the activation energy, $E_{\mathrm{a}}\left(\mathrm{J} \mathrm{mol}^{-1}\right)$ were determined based on the Arrhenius equation, which relates the reaction rate constant, $k$ (hours ${ }^{-1}$ ), calculated as the inverse of the OS values, with the inverse of the absolute temperature $\left(1 / T\right.$, in $\left.\mathrm{K}^{-1}\right)$, after its logarithmic linearization, using the intercept and the slope values, respectively, according to Eqs. 4-6:

$$
\begin{aligned}
\log _{10}\left(k, \text { hours }^{-1}\right) & =\text { intercept }_{\text {II }}+\text { slope }_{I I} \times\left(\frac{1}{T}\right) \\
& =\log _{10}\left(A, \text { hours }^{-1}\right)-\frac{E_{a}}{R} \times\left(\frac{1}{T}\right)
\end{aligned}
$$

being $R$ the molar gas constant (equal to $8.314 \mathrm{~J} \mathrm{~mol}^{-1} \mathrm{~K}^{-1}$ ) and,

$A\left(\right.$ hours $\left.^{-1}\right)=10^{\text {intercept }_{I I}}$

$E_{a}\left(\mathrm{~J} \mathrm{~mol}^{-1}\right)=-R \times$ slope $_{I I}$

The use of this approach assumes that lipid oxidation of oils in an excess of oxygen may be described by a firstorder exothermic process (Ciemniewska-Żytkiewicz et al., 2014; Symoniuk et al., 2018). Since in empirical Arrhenius plots, the linearity (Eq. 4), can be enforced, due to the low number of experimental points used, the existence of positive or negative deviations to the Arrhenius mechanism (sub- or super-Arrhenius behaviors, respectively) was evaluated following a graphical approach (Aquilanti et al., 2010, 2017; Romagnoli et al., 2018; Silva et al., 2013).

Similarly, the enthalpies $\left(\Delta \mathrm{H}^{++}\right.$, in $\left.\mathrm{J} \mathrm{mol}^{-1}\right)$ and entropies $\left(\Delta \mathrm{S}^{++}\right.$, in $\left.\mathrm{J} \mathrm{mol}^{-1} \mathrm{~K}^{-1}\right)$ of activation can be calculated by the parameters of the regression line between $\log _{10}\left(\frac{k}{T}\right)$ versus the inverse of the absolute temperature $\left(1 / T\right.$, in $\left.\mathrm{K}^{-1}\right)$ as shown in Eqs 7-9: 


$$
\begin{aligned}
\log _{10}\left(\frac{k}{T}\right)= & \text { intercept }_{I I I}+\text { slope }_{I I I} \times\left(\frac{1}{T}\right)=\log _{10}\left(\frac{k_{B}}{h}\right) \\
& +\left(\frac{\Delta S^{++}}{\ln (10) \times R}\right)-\left(\frac{\Delta H^{++}}{\ln (10) \times R}\right) \times\left(\frac{1}{T}\right)
\end{aligned}
$$

being $k_{B}$ the Boltzman constant $\left(k_{B}=1.380658 \times 10^{-23} \mathrm{~J} \mathrm{~K}^{-1}\right)$ and $h$ the Planck's constant $(h=6.6260755 \times$ $10^{-34} \mathrm{~J} \mathrm{~s}=1.8405765 \times 10^{-37} \mathrm{~J}$ hour), and so,

$\Delta H^{++}=-$slope $_{I I I} \times \ln (10) \times R$

$\Delta S^{++}=\ln (10) \times R \times\left[\right.$ intercept $\left._{I I I}-\log _{10}\left(\frac{k_{\mathrm{B}}}{h}\right)\right]$

Finally, the Gibbs free energy $\left(\Delta \mathrm{G}^{++}\right.$, in $\left.\mathrm{J} \mathrm{mol}^{-1}\right)$ of activation at a given temperature $T$ can be calculated from Eq. 10:

$\Delta \mathrm{G}^{++}=\Delta \mathrm{H}^{++}-T \times \Delta \mathrm{S}^{++}$

where $T$ is the absolute temperature (in $\mathrm{K}$ ).

\section{Statistical Analysis}

The existence of possible significant effects of the olive oil type ( $c v$. Arbequina oil, blend oil and $c v$. Cobrançosa oil with different bitter-pungent sensations) on the physicochemical quality indices (FA, PV, $K_{232}$ and $K_{268}$ extinction coefficients), TPC and OS values at the five different temperatures $\left(120,130,140,150\right.$ and $\left.160^{\circ} \mathrm{C}\right)$, was statistically evaluated through the one-way ANOVA, followed by the post-hoc multicomparison Tukey's test, in the case that a significant statistical effect was observed $(P$-value $<0.050)$. Linear regressions were performed (Eqs 1, 4, and 7) aiming to determine kinetic and thermodynamic parameters (Eqs 2-3, 5-6, and 8-10), for the three types of olive oils studied, being the quality of each linear fit assessed using the determination coefficient $\left(R^{2}\right)$. The possible statistical significant effects of the olive oil type on the calculated values of $T_{\mathrm{C}}, Q_{10}, A, E_{\mathrm{a}}, \Delta \mathrm{H}^{++}, \Delta \mathrm{S}^{++}$, and $\Delta \mathrm{G}^{++}$, were also investigated using the one-way ANOVA followed by the Tukey's test. Finally, the possibility of using the kinetic parameters as olive oil classifiers was further evaluated through the unsupervised PCA after normalizing the weight of each variable in the PCA by scaling and centering techniques. The kinetic parameters with the highest discrimination potential were identified by applying a LDA coupled with the SA meta-heuristic variable selection algorithm, which performance was checked using a leave-one-out cross-validation (LOO-CV) procedure. The statistical analyses were performed using the Subselect (Cadima et al., 2004; Kuhn and Johnson, 2013) and MASS (Venables and Ripley, 2002) packages of the open-source statistical program R (version 2.15.1) or the Data Analysis Toolpak of
Excel software (Microsoft Office Professional Plus 2016), at a 5\% significance level.

\section{Compliance with Ethical Standards}

This article does not contain any studies with human participants or animals performed by any of the authors.

\section{Results and Discussion}

\section{Physicochemical, Total Phenols, and Oxidative Stability of Olive Oils}

The physicochemical quality data (FA, PV, $K_{232}$, and $\left.K_{268}\right)$, the TPC and the OS at different temperatures $\left(120-160{ }^{\circ} \mathrm{C}\right)$ were evaluated for $c v s$. Arbequina and Cobrançosa olive oils and for the blend olive oil, with different intensities of the bitter-pungent sensation (Table 1). The physicochemical data showed that the oils, independently of the olive cultivar, fulfilled the legal thresholds established by the European Commission (EC) regulations for EVOO quality grade classification (Commission Delegated Regulation [EU] 2015/1830, 2015; Sacchi et al., 2017). In which concerns the TPC, the values found although apparently low compared to other oils produced from other olive cultivars (Gharby et al., 2016), are in agreement with those reported by other researchers for $c v$. Cobrançosa oil (Casal et al., 2010; Neves et al., 2011; Sousa et al., 2015) and $c v$. Arbqequina oil (Borges et al., 2017b, 2019). For $c v$. Cobrançosa oils, other researchers reported higher TPC (Machado et al., 2015; Peres et al., 2016a, b), confirming that factors like agro-climatic conditions, olive maturation stage at harvest, olive storage conditions as well as oil extraction practices, and storage time and its conditions may influence TPC.

The results obtained in this work showed that the olive cultivar (cvs. Arbequina, Cobrançosa or blend cultivars) had a statistical significant effect on PV, $K_{232}$, TPC, and OS determined at $120-160{ }^{\circ} \mathrm{C}(P$-value $<0.0001$ for the one-way ANOVA). The PV and $K_{232}$ levels decreased in the order $c v$. Arbequina oil (low bitter-pungent) $>$ blend oil (moderate bitter-pungent) $>c v$. Cobrançosa oil (intense bitter-pungent) and the TPC and the OS values increased inversely ( $c v$. Arbequina oil $<$ blend oil $<c v$. Cobrançosa oil). As expected, oils with higher TPC showed a greater resistance to oxidation (i.e., higher OS values), being oils with the lower bitter-pungent sensation the less thermally stable. For each olive oil type, the OS values significantly decreased with the increase of the oxidation temperature. Also, and as envisioned, the selected monovarietal and blend oils could be split in three groups taking into account 
Table 1 Physicochemical (free acidity, extinction coefficients, and peroxide values), total phenols and oxidative stability data of the two monovarietal (cvs. Arbequina and Cobrançosa) and one blend olive oil studied (mean value \pm SD calculated based on the data determined for five independent samples of each olive oil type)

\begin{tabular}{|c|c|c|c|c|}
\hline \multirow[t]{2}{*}{ Parameters $^{\#}$} & \multicolumn{3}{|c|}{ Olive oil class ${ }^{\mathrm{a}}$} & \multirow{2}{*}{$\begin{array}{l}P \text {-value }{ }^{\mathrm{b}} \text { (one- } \\
\text { way ANOVA) }\end{array}$} \\
\hline & $\begin{array}{l}c v \text {. Arbequina oil with low } \\
\text { bitter-pungent intensity }\end{array}$ & $\begin{array}{l}\text { Blend oil with moderate } \\
\text { bitter-pungent intensity }\end{array}$ & $\begin{array}{l}c v \text {. Cobrançosa oil with intense } \\
\text { bitter-pungent intensity }\end{array}$ & \\
\hline FA $(\%)$ & $0.17 \pm 0.06$ & $0.23 \pm 0.00$ & $0.23 \pm 0.03$ & 0.2519 \\
\hline $\mathrm{PV}\left(\mathrm{mEq} \mathrm{O} \mathrm{O}_{2} \mathrm{~kg}^{-1}\right)$ & $9.4 \pm 0.5 \mathrm{a}$ & $6.9 \pm 0.5 b$ & $3.6 \pm 0.5 \mathrm{c}$ & $<0.0001$ \\
\hline$K_{232}$ & $1.978 \pm 0.0484 \mathrm{a}$ & $1.196 \pm 0.0424 b$ & $1.173 \pm 0.082 b$ & $<0.0001$ \\
\hline$K_{268}$ & $0.168 \pm 0.014$ & $0.166 \pm 0.012$ & $0.176 \pm 0.010$ & 0.3957 \\
\hline$T P C(\mathrm{mg} \mathrm{CAE} / \mathrm{kg})$ & $88 \pm 7 c$ & $112 \pm 6 b$ & $144 \pm 4 a$ & $<0.0001$ \\
\hline $\mathrm{OS}_{120^{\circ} \mathrm{C}}$ (hours) & $7.1 \pm 0.2 \mathrm{cA}$ & $12.2 \pm 0.7 \mathrm{bA}$ & $13.6 \pm 0.7 \mathrm{aA}$ & $<0.0001$ \\
\hline $\mathrm{OS}_{130^{\circ} \mathrm{C}}$ (hours) & $3.4 \pm 0.1 \mathrm{cB}$ & $5.7 \pm 0.1 \mathrm{bB}$ & $6.1 \pm 0.0 \mathrm{aB}$ & $<0.0001$ \\
\hline $\mathrm{OS}_{140{ }^{\circ} \mathrm{C}}$ (hours) & $2.0 \pm 0.0 \mathrm{cC}$ & $3.1 \pm 0.1 \mathrm{bC}$ & $3.2 \pm 0.1 \mathrm{aC}$ & $<0.0001$ \\
\hline $\mathrm{OS}_{150{ }^{\circ} \mathrm{C}}$ (hours) & $1.2 \pm 0.1 \mathrm{cD}$ & $1.8 \pm 0.0 \mathrm{bD}$ & $1.9 \pm 0.1 \mathrm{aD}$ & $<0.0001$ \\
\hline $\mathrm{OS}_{160{ }^{\circ} \mathrm{C}}$ (hours) & $0.9 \pm 0.0 \mathrm{cE}$ & $1.1 \pm 0.0 \mathrm{bE}$ & $1.2 \pm 0.0 \mathrm{aE}$ & $<0.0001$ \\
\hline $\begin{array}{l}P \text {-value }{ }^{c} \text { (one-way } \\
\text { ANOVA) }\end{array}$ & $<0.0001$ & $<0.0001$ & $<0.0001$ & \\
\hline
\end{tabular}

${ }^{\#} \mathrm{FA}$, free acidity; $\mathrm{K}_{232}$ and $\mathrm{K}_{268}$, extinction coefficients at 232 and $270 \mathrm{~nm}$, respectively; OS, oxidative stability; PV, peroxide values; TPC, total phenols content.

${ }^{a}$ Classification based on the olive cultivar information provided by the oil producer and on the bitter-pungent sensations perceived by trained panelists just after oil production at the olive oil mill.

${ }^{\mathrm{b}}$ For each line, a $P$-value $<0.05$ (bold and italic) means that the mean value of the evaluated parameter of at least one olive oil type significantly differ from the others, according to the one-way ANOVA. In each line, different lowercase letters mean significant statistical differences of the parameter under evaluation, at a 5\% significance level, according to multiple comparison Tukey's HSD test.

${ }^{\mathrm{c}}$ For each column, a $P$-value $<0.05$ (bold and italic) means that the mean value of the oxidative stability (OS) determined at least one oxidation temperature significantly differ from the others, according to the one-way ANOVA. In each column, different uppercase letters mean significant statistical differences of the parameter under evaluation, at a 5\% significance level, according to multiple comparison Tukey's HSD test.

the binomial olive cultivar/TPC corresponding to low bitter-pungent, moderate bitter-pungent, and intense bitterpungent olive oils. The OS experimental data were of the same magnitude but, in general, higher than those reported in the literature $\left(16.6-0.6\right.$ hours for $120-150{ }^{\circ} \mathrm{C}$, respectively) (Ciemniewska-Żytkiewicz et al., 2014; Farhoosh et al., 2008; Farhoosh and Hoseini-Yazdi, 2013, 2014; Gharby et al., 2016; Hasenhuettl and Wan, 1992; Heidarpour and Farhoosh, 2018; Ostrowska-Ligeza et al., 2010). A possible explanation is that the olive oil OS values are not only influenced by the TPC but also significantly vary with other factors like the olive cultivar as shown by Mateos et al. (2006).

\section{Reaction Rate Constants of Olive Oils at Different Temperatures $\left(120-160{ }^{\circ} \mathrm{C}\right)$ Calculated Using the OS Data}

As previously pointed out, the reaction rate constants $(k$, hours $^{-1}$ ) of each olive oil type (monovarietal or blend oils with different bitter-pungent intensities and TPC) were calculated, at each studied temperature, as the inverse of the OS determined using the Rancimat method. The calculated mean $k$ values $( \pm \mathrm{SD})$ are shown in Table 2 . Similarly, but with an opposite trend, the binomial olive cultivar/TPC (or the bitter-pungent sensation) significantly influenced the reaction rate constants $(P$-value $<0.0001$, one-way ANOVA), which were also affected by the oxidation temperature ( $P$-value $<0.0001$, one-way ANOVA). Thus, for each studied temperature, $k$ values decreased with the increase of the TPC of the olive oils $(P$-value $<0.0001$ for the Tukey's test, in the order $c v$. Arbequina oil $\rightarrow$ blend oil $\rightarrow c v$. Cobrançosa oil). On the contrary, for each olive oil type, the $k$ values increased when the oxidation temperature increased ( $P$-value $<0.0001$ for the Tukey's test), being the observed trend similar to that reported in the literature for reaction rate constants of olive oils assessed between 100 and $170{ }^{\circ} \mathrm{C}$, although the literature $k$ values (Ciemniewska-Żytkiewicz et al., 2014; Farhoosh et al., 2008; Gharby et al., 2016; Ostrowska-Ligeza et al., 2010) were higher (ranging from 0.060 to 3.284 hours $^{-1}$ at $120-160{ }^{\circ} \mathrm{C}$ ) than those found in the present study. Similar trends, as those observed in the present study, can be inferred from the OS data reported by Farhoosh and Hoseini-Yazdi (2014) if the olive oils were grouped according to their different commercial quality grades or, in 
Table 2 Reaction rate constants, temperature coefficients, temperature acceleration factors, frequency factors, activation energies, enthalpies and entropies of activation, and free Gibbs energies (mean value $\pm \mathrm{SD}$ ) of olive oils with different TPC ( $c v$. Arbequina, blend oil and $c v$. Cobrançosa)

\begin{tabular}{|c|c|c|c|c|}
\hline \multirow{2}{*}{$\begin{array}{l}\text { Kinetic and thermodynamic } \\
\text { parameters }{ }^{\S}\end{array}$} & \multicolumn{3}{|c|}{ Olive oils ${ }^{\mathrm{a}}$} & \multirow{2}{*}{$\begin{array}{l}P \text {-value }{ }^{\mathrm{b}} \text { (one- } \\
\text { way ANOVA) }\end{array}$} \\
\hline & $\begin{array}{l}c v . \text { Arbequina oil with low } \\
\text { bitter-pungent intensity }\end{array}$ & $\begin{array}{l}\text { Blend oil with moderate } \\
\text { bitter-pungent intensity }\end{array}$ & $\begin{array}{c}c v . \text { Cobrançosa oil with } \\
\text { intense bitter-pungent } \\
\text { intensity }\end{array}$ & \\
\hline$k_{120}{ }^{\circ} \mathrm{C}\left(\right.$ hours $\left.^{-1}\right)$ & $0.141 \pm 0.004 \mathrm{aE}$ & $0.082 \pm 0.004 \mathrm{bE}$ & $0.074 \pm 0.004 \mathrm{cE}$ & $<0.0001$ \\
\hline$k_{130^{\circ} \mathrm{C}}\left(\right.$ hours $\left.^{-1}\right)$ & $0.295 \pm 0.008 \mathrm{aD}$ & $0.177 \pm 0.002 \mathrm{bD}$ & $0.163 \pm 0.001 \mathrm{cD}$ & $<0.0001$ \\
\hline$k_{140}{ }^{\circ} \mathrm{C}\left(\right.$ hours $\left.^{-1}\right)$ & $0.498 \pm 0.012 \mathrm{aC}$ & $0.322 \pm 0.006 \mathrm{bC}$ & $0.309 \pm 0.006 \mathrm{bC}$ & $<0.0001$ \\
\hline$k_{150^{\circ} \mathrm{C}}\left(\right.$ hours $\left.^{-1}\right)$ & $0.821 \pm 0.038 \mathrm{aB}$ & $0.564 \pm 0.008 \mathrm{bB}$ & $0.537 \pm 0.019 \mathrm{bB}$ & $<0.0001$ \\
\hline$k_{160}{ }^{\circ} \mathrm{C}\left(\right.$ hours $\left.^{-1}\right)$ & $1.122 \pm 0.028 \mathrm{aA}$ & $0.906 \pm 0.004 \mathrm{bA}$ & $0.854 \pm 0.028 \mathrm{cA}$ & $<0.0001$ \\
\hline$P$-value ${ }^{\mathrm{c}}$ (one-way ANOVA) & $<0.0001$ & $<0.0001$ & $<0.0001$ & \\
\hline$\overline{T_{C}\left({ }^{\circ} \mathrm{C}^{-1}\right)}$ & $-0.0224 \pm 0.0004 b$ & $-0.0259 \pm 0.0005 a$ & $-0.0265 \pm 0.0004 a$ & $<0.0001$ \\
\hline$Q_{10}$ & $1.68 \pm 0.02 b$ & $1.81 \pm 0.02 \mathrm{a}$ & $1.84 \pm 0.02 \mathrm{a}$ & $<0.0001$ \\
\hline$A \times 10^{8}\left(\right.$ hours $\left.^{-1}\right)$ & $9.5 \pm 4.3 b$ & $161.3 \pm 67.4 \mathrm{a}$ & $271.4 \pm 97.3 \mathrm{a}$ & 0.0002 \\
\hline$E_{\mathrm{a}}\left(\mathrm{kJ} \mathrm{mol}^{-1}\right)$ & $73.43 \pm 1.32 b$ & $84.50 \pm 1.66 \mathrm{a}$ & $86.52 \pm 1.41 \mathrm{a}$ & $<0.0001$ \\
\hline$\Delta H^{++}\left(\mathrm{kJ} \mathrm{mol}^{-1}\right)$ & $70.00 \pm 1.32 b$ & $81.07 \pm 1.67 \mathrm{a}$ & $83.09 \pm 1.41 \mathrm{a}$ & $<0.0001$ \\
\hline$\Delta S^{++}\left(\mathrm{J} \mathrm{mol}^{-1} \mathrm{~K}^{-1}\right)$ & $-152.66 \pm 3.19 \mathrm{a}$ & $-129.28 \pm 3.94 b$ & $-124.80 \pm 3.52 b$ & $<0.0001$ \\
\hline$\overline{\Delta G_{120^{\circ} \mathrm{C}}^{++}\left(\mathrm{kJ} \mathrm{mol}^{-1}\right)}$ & $130.02 \pm 0.08 \mathrm{cE}$ & $131.90 \pm 0.12 \mathrm{bE}$ & $132.16 \pm 0.11 \mathrm{aE}$ & $<0.0001$ \\
\hline$\Delta G_{130^{\circ} \mathrm{C}}^{+}\left(\mathrm{kJ} \mathrm{mol}^{-1}\right)$ & $131.54 \pm 0.06 \mathrm{cD}$ & $133.19 \pm 0.08 \mathrm{bD}$ & $133.40 \pm 0.10 \mathrm{aD}$ & $<0.0001$ \\
\hline$\Delta G_{140^{\circ} \mathrm{C}}^{++}\left(\mathrm{kJ} \mathrm{mol}^{-1}\right)$ & $133.07 \pm 0.04 \mathrm{cC}$ & $134.48 \pm 0.04 \mathrm{bC}$ & $134.65 \pm 0.12 \mathrm{aC}$ & $<0.0001$ \\
\hline$\Delta G_{150^{\circ} \mathrm{C}}^{++}\left(\mathrm{kJ} \mathrm{mol}^{-1}\right)$ & $134.60 \pm 0.05 \mathrm{bB}$ & $135.78 \pm 0.02 \mathrm{aB}$ & $135.90 \pm 0.13 \mathrm{aB}$ & $<0.0001$ \\
\hline$\Delta G_{160^{\circ} \mathrm{C}}^{++}\left(\mathrm{kJ} \mathrm{mol}^{-1}\right)$ & $136.12 \pm 0.07 \mathrm{bA}$ & $137.07 \pm 0.04 \mathrm{aA}$ & $137.15 \pm 0.16 \mathrm{aA}$ & $<0.0001$ \\
\hline$P$-value ${ }^{\mathrm{c}}$ (one-way ANOVA) & $<0.0001$ & $<0.0001$ & $<0.0001$ & \\
\hline
\end{tabular}

${ }_{\mathrm{k}}$, reaction rate constant in hours ${ }^{-1}$ calculated as the inverse of the $\mathrm{OS}$ values reported in Table $1 ; \mathrm{T}_{\mathrm{C}}$, temperature coefficient in ${ }^{\circ} \mathrm{C}^{-1}(\mathrm{Eq} .2)$; $\mathrm{Q}_{10}$, temperature acceleration factor (Eq. 3); A, frequency factor in hours ${ }^{-1}$ (Eq. 5); Ea, activation energy in kJ mol ${ }^{-1}\left(\mathrm{Eq}^{\circ}\right.$ ) 6); $\Delta \mathrm{H}^{++}$, enthalpy of activation in $\mathrm{kJ} \mathrm{mol}^{-1}$ (Eq. 8); $\Delta \mathrm{S}^{++}$, entropy of activation in $\mathrm{J} \mathrm{mol}^{-1} \mathrm{~K}^{-1}$ (Eq. 9); $\Delta \mathrm{G}^{++}$, free Gibbs energy in kJ mol ${ }^{-1}$ at each temperature studied (Eq. 10).

a Olive oils were grouped according to the olive cultivar and total phenols contents (TPC) found as: TPC $=88 \pm 7 \mathrm{mg} \mathrm{CAE} / \mathrm{kg}$ olive oil, $c v$. Arbequina oil; TPC $=112 \pm 6 \mathrm{mg} \mathrm{CAE} / \mathrm{kg}$ olive oil, blend oil; and, TPC $=144 \pm 4 \mathrm{mg}$ CAE $/ \mathrm{kg}$ olive oil, $c v$. Cobrançosa oil, which corresponded to different bitter-pungent intensities.

${ }^{\mathrm{b}}$ For each line, a $P$-value $<0.05$ (bold and italic) means that the mean value of the evaluated parameter of at least one olive oil type/TPC significantly differ from the others, according to the one-way ANOVA. In each line, different lowercase letters mean significant statistical differences of the parameter under evaluation, at a 5\% significance level, according to multiple comparison Tukey's HSD test.

${ }^{\mathrm{c}}$ For each column, a $P$-value $<0.05$ (bold and italic) means that the of reaction rate constant $(k)$ or the mean value of the free Gibbs energy $\left(\Delta \mathrm{G}^{++}\right)$ calculated at least one oxidation temperature significantly differ from the others, according to the one-way ANOVA. In each column, different uppercase letters mean significant statistical differences of the parameter under evaluation, at a 5\% significance level, according to multiple comparison Tukey's HSD test.

a lower extent, with the values that may be estimated from those reported by Heidarpour and Farhoosh (2018). Similarly, Gharby et al. (2016) found that an increase of the polyphenol content of monovarietal oils corresponded to a lower $k$ values (i.e., higher OS values). The observed differences of the $k$ values (as well as of the OS values) can be attributed, to a certain extent, to the expected different fatty acid composition and TPC of the olive oils evaluated in the different research works (Farhoosh et al., 2008), which were obtained from different olive cultivars produced in different geographical origins (e.g., cvs. Arbequina, Koroneiki, Picholine, Picual, Roghani, and Zard from Iran, Morocco).

\section{Kinetic Parameters and Thermodynamic Parameters of Olive Oils}

The $T_{\mathrm{C}}$ and $Q_{10}$ kinetic parameters were calculated from the slope values of the linear regressions (Eq. 1) established between the decimal logarithm of OS and the $T$ values using Eqs 2 and 3. For the three olive oil groups, satisfactory linear regressions could be obtained (determination coefficients, $R^{2}$, varying between 0.978 to 0.994 ). The mean values as well as the respective SD are also presented in Table 2, being this kind of data reported for the first time for Portuguese olive oils possessing different bitter-pungent intensities. As can be observed, the TPC (and in which 
concerns the present study, the olive cultivar) of the oils had a statistically significant effect on the $T_{\mathrm{C}}$ values $(P$ value $<0.0001$ for one-way ANOVA), increasing in the following binomial order $c v$. Arbequina oil with low TPC $<$ blend oil with medium TPC $\cong c v$. Cobrançosa oil with high TPC. A similar trend was found for $Q_{10}$ values. The observed variability of $T_{C}$ and $Q_{10}$ imply, as discussed by Farhoosh et al. (2008), that the production of volatile acids (lipid oxidation), under the studied Rancimat conditions, was influenced by the olive cultivar and probably by the respective TPC (or bitter-pungent intensities), affecting the relative stability of the oils. The $T_{C}$ values of the olive oils studied in this work (varying from -0.0371 to $-0.0224{ }^{\circ} \mathrm{C}^{-1}$ ) were in accordance with the literature data or slightly lower (in absolute value) (CiemniewskaŻytkiewicz et al., 2014; Farhoosh and Hoseini-Yazdi, 2014; Gharby et al., 2016; Hasenhuettl and Wan, 1992; Heidarpour and Farhoosh, 2018; Mahdavianmehr et al., 2016; Mateos et al., 2006). The literature data pointed out that $T_{C}$ values highly depend on the quality grade and chemical composition of the olive oil (e.g., fatty acids and individual phenolic compositions), olive cultivar, or even of the olive oil sample for the same cultivar. The $Q_{10}$ values determined in this study (Table 2) varied between 1.68 and 1.84 being of the same order of magnitude but lower than those reported in the literature (2.08-2.35) for different olive oils (Farhoosh et al., 2008; Farhoosh and HoseiniYazdi, 2014; Gharby et al., 2016; Heidarpour and Farhoosh, 2018) or for pure olive oil triacylglycerols (1.95) (Mahdavianmehr et al., 2016). It should be pointed out that based on the data reported by Gharby et al. (2016) the olive cultivar (cvs. Arbequina, Picholine, Picual and Koroneiki) and the TPC (varying from $136 \pm 25$ to $320 \pm 30 \mathrm{mg} \mathrm{kg}^{-1}$ ) of olive oils did not highly affect the $Q_{10}$ values (which varied from 2.0 to 2.2). Finally, it should be noticed that oils with low absolute $T_{C}$ values and $Q_{10}$ values are envisaged since they are thermally more stable, meaning that greater temperature changes would be needed to induce the same extent of changes in the lipid oxidation rate (Farhoosh and Hoseini-Yazdi, 2014; Mahdavianmehr et al., 2016).

The frequency factor $(A)$ and the activation energy $\left(E_{\mathrm{a}}\right)$ were determined (Table 2) from the Arrhenius equation, using $k$ and respective $T$ values (Eq. 4 with satisfactory fits: $0.984 \leq R^{2} \leq 0.998$ ). It should be noticed that the semilogarithmic relationships between $k$ and 1/T (Fig. 1) show a concave curvature (i.e., a super-Arrhenius behavior) (Aquilanti et al., 2010, 2017; Romagnoli et al., 2018; Silva et al., 2013), which may indicate a deviation from the Arrhenius lipid oxidation mechanism, being the nonArrhenius behavior more pronounced for the $c v$. Arbequina olive oils, which had lowest TPC (high negative second order derivative and highest difference between the linear and second order polynomial coefficients of determination,
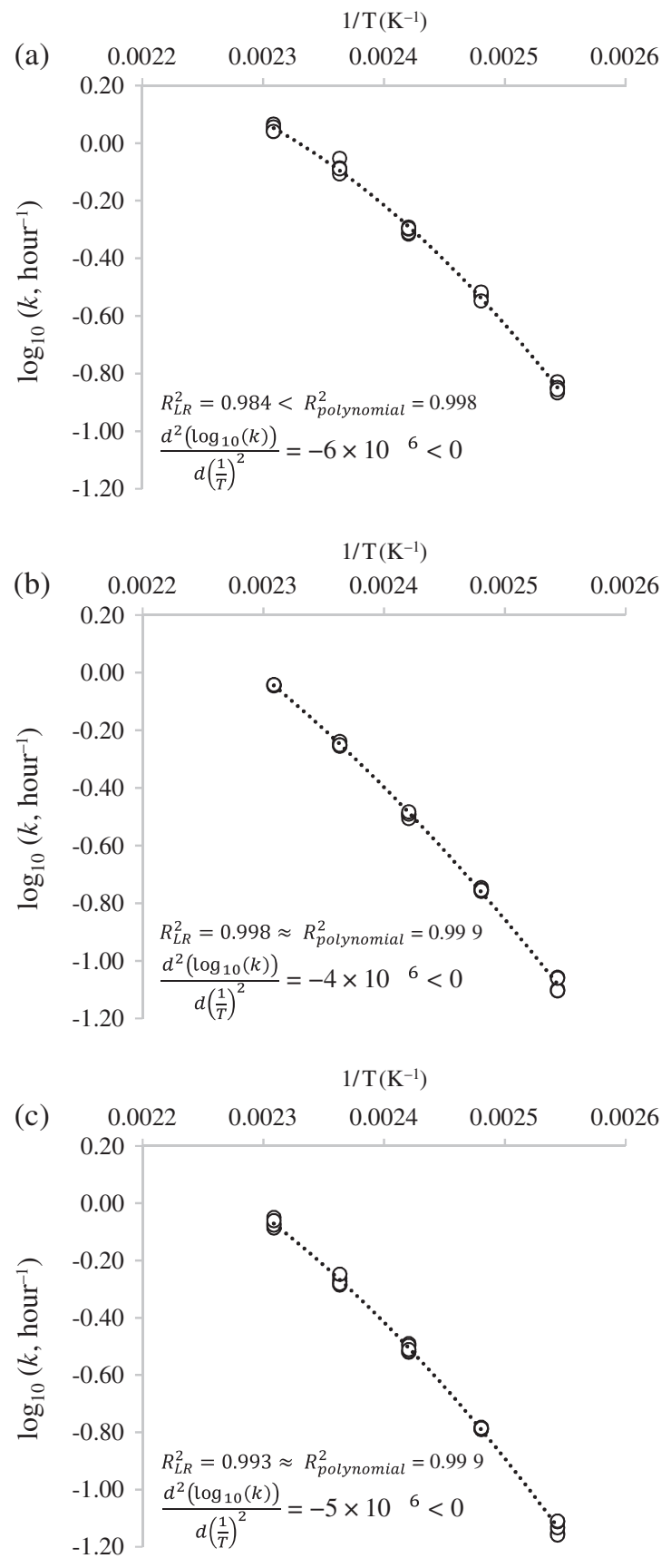

Fig. 1 Arrhenius versus non-Arrhenius (i.e., super-Arrhenius) behavior: linear versus 2 nd order polynomial semilogarithm relationship between the reaction constant rate $(k)$ and the inverse of the absolute temperature (1/T) for olive oils with different TPC: (a) $c v$. Arbequina (low bitter-pungent intensity); (b) blend oil (moderate bitter-pungent intensity); and, (c) $c v$. Cobrançosa (intense bitter-pungent intensity)

$R_{\mathrm{LR}}^{2}$ and $R_{\text {polynomial }}^{2}$ ). As shown in Table 2, the binomial olive cultivar/TPC (or the bitter-pungent intensity) significantly affects both kinetic parameters $(P$-value $\leq 0.0002$, for one-way ANOVA), with higher values observed for higher TPC ( $c v$. Arbequina < blend $\cong c v$. Cobrançosa oil), being the increase marked between $c v$. Arbequina oil with 
lower TPC and blend oil with medium TPC (i.e, $c v$. Arbequina to blend oil). These findings imply that to a certain extent the formation reaction of the secondary lipid oxidation products (mainly volatile acids), under the studied Rancimat conditions, was possibly influenced by the bitter-pungent intensity and by the TPC of each olive oil, which, in this study is directly related with the olive cultivar studied. Olive oils with high $E_{\mathrm{a}}$ values are desirable since it will mean a high resistance to lipid oxidation, and an increase of $E_{\mathrm{a}}$ would turn out in a delay of the onset of the initial oxidation process, responsible for the bond scission that results on the formation of primary oxidation products (de Man et al., 1987; Farhoosh et al., 2008). The calculated $A$ values (mean values varying from $9.5 \times 10^{8}-271.4 \times$ $10^{8}$ hours $^{-1}$ ) were in agreement with those reported by Mahdavianmehr et al. (2016) for pure olive oil triacylglycerols $\left(261 \times 10^{8}\right.$ hours $\left.^{-1}\right)$ but much lower than those $\left(0.83 \times 10^{12}\right.$ to $3.94 \times 10^{15}$ ) reported for olive oils by other research teams (Ciemniewska-Żytkiewicz et al., 2014; Farhoosh et al., 2008; Farhoosh and Hoseini-Yazdi, 2014; Gharby et al., 2016; Heidarpour and Farhoosh, 2018; Ostrowska-Ligeza et al., 2010). Likewise, the $E_{\mathrm{a}}$ values obtained for the three types of EVOO evaluated $\left(73.4-86.5 \mathrm{~kJ} \mathrm{~mol}^{-1}\right)$ were greater than those $\left(68.42 \mathrm{~kJ} \mathrm{~mol}^{-1}\right)$ reported for other olive oils by Mahdavianmehr et al. (2016), similar to the value $\left(86.86 \mathrm{~kJ} \mathrm{~mol}^{-1}\right)$ found by Farhoosh et al. (2008) and lower than those determined $\left(89.46-106.83 \mathrm{~kJ} \mathrm{~mol}^{-1}\right.$ ) by other researchers (CiemniewskaŻytkiewicz et al., 2014; Farhoosh and Hoseini-Yazdi, 2014; Gharby et al., 2016; Heidarpour and Farhoosh, 2018; Ostrowska-Ligeza et al., 2010). These differences may be attributed to the expected different fatty acids profiles and contents of oils produced from different olive cultivars and with different geographical origins, since it has been reported that high contents of PUFA would lower the $E_{\mathrm{a}}$ values, while high MUFA and SFA contents would result in a rise of the $E_{\mathrm{a}}$ value (Ciemniewska-Żytkiewicz et al., 2014; Farhoosh and Hoseini-Yazdi, 2014). Although other researchers did not find any marked relationship between $E_{\mathrm{a}}$ and OS values (Farhoosh and Hoseini-Yazdi, 2014; Gharby et al., 2016), in the present study, a linear trend $(+0.939 \leq R$ Pearson $\leq+0.988$ ) was observed between those two parameters.

Based on the activated complex theory, $\Delta \mathrm{H}^{++}$and $\Delta \mathrm{S}^{++}$ values were determined (Table 2) using the intercept and slope values of the linear regression between $\log _{10}\left(\frac{k}{T}\right)$ and $1 / T$ (Eq. 7, $0.983 \leq R^{2} \leq 0.998$ ). Similar to the previous discussed kinetic parameters, the binomial olive cultivar/TPC (and by consequence the bitter-pungent intensity) significantly affects $\Delta \mathrm{H}^{++}$and $\Delta \mathrm{S}^{++}(P$-value $<0.0001$, for oneway ANOVA). The $\Delta \mathrm{H}^{++}$values $\left(70.00-83.09 \mathrm{~kJ} \mathrm{~mol}^{-1}\right)$ were positive and increased as the TPC raised (in the order, $c v$. Arbequina oil $\rightarrow$ blend oil $\rightarrow c v$. Cobrançosa oil), reflecting the endothermic nature of the formation reaction of the activated complexes. The $\Delta \mathrm{S}^{++}$(mean values varying from -152.66 to $-129.28 \mathrm{~J} \mathrm{~mol}^{-1} \mathrm{~K}^{-1}$ ) had a negative sign showing that the lipid oxidation is an endergonic process, which provided transition state structures (i.e., activated complexes with a transient existence) more ordered than the reactants in the ground state and thus suggesting an association mechanism in which the reactant species joined to each other to form the transition states (de Sousa et al., 2019; Farhoosh and Hoseini-Yazdi, 2014). Also, from Table 2, it can be concluded that $c v$. Arbequina olive oils, with lower TPC, had significantly greater negative $\Delta \mathrm{S}^{++}$values than $c v$. Cobrançosa olive oils, with higher TPC, implying, contrary to what was expected, a lesser potential of the activated complex for oxidation reaction. Moreover, it should be remarked that the $\Delta \mathrm{H}^{++}$and $\Delta \mathrm{S}^{++}$ data are, in general, in agreement with those reported in the literature by other researchers. The $\Delta \mathrm{H}^{++}$calculated in this study are slightly greater than those found by Mahdavianmehr et al. (2016) for pure triacylglycerols extracted from olive oils $\left(65.50 \mathrm{~kJ} \mathrm{~mol}^{-1}\right)$, of the same magnitude as that reported by Farhoosh et al. (2008) for olive oils $\left(83.64 \mathrm{~kJ} \mathrm{~mol}^{-1}\right)$ and lower than those (varying from 91.03 to $103.61 \mathrm{~kJ} \mathrm{~mol}^{-1}$ ) reported by Farhoosh and HoseiniYazdi (2014), Gharby et al. (2016) and Heidarpour and Farhoosh (2018), showing the expected influence of factors like olive cultivar and chemical composition of oils. Nevertheless, the results confirmed the endothermic nature of the formation reaction of the activated complexes and the high variability with the type of olive oil studied. In which concerns $\Delta \mathrm{S}^{++}$, the values found in this study are in accordance with those reported by Mahdavianmehr et al. (2016) for pure triacylglycerols of olive oils $\left(-142.45 \mathrm{~J} \mathrm{~mol}^{-1} \mathrm{~K}^{-1}\right)$, but significantly more negative than those reported in the literature for olive oils from other cultivars (varying generally between -116.66 to $-14.55 \mathrm{~J} \mathrm{~mol}^{-1} \mathrm{~K}^{-1}$ ) (Farhoosh et al., 2008; Farhoosh and Hoseini-Yazdi, 2014; Gharby et al., 2016; Heidarpour and Farhoosh, 2018). The variability of the $\Delta \mathrm{S}^{++}$values (data from this study and literature data) showed that, although the activated complexes of olive oils had a low potential for oxidation reaction, the oxidation rate highly depended on the type (e.g., quality grade) and characteristics of each olive oil (namely, olive cultivar and TPC, and probably also due to the specific fatty acids composition, phenolic profiles, and other bioactive constituents). Moreover, linear and polynomial directly proportional correlations could be established for $E_{\mathrm{a}}$ versus $\Delta \mathrm{H}^{++}$ and $A$ versus $\Delta \mathrm{S}^{++}$(correlation coefficients equal to 1.000 and +0.998 , respectively), which is in agreement with the transition-state theory of reaction rates (Farhoosh and Hoseini-Yazdi, 2014; Heidarpour and Farhoosh, 2018). Additionally, the data (Table 2) allowed inferring that the ratio $E_{\mathrm{a}} / \Delta \mathrm{H}^{++}$is almost constant for all the olive oils under study (only a slight increase is observed, seeming 
independent from the olive cultivar and TPC) but on the contrary, the ratio $A / \Delta \mathrm{S}^{++}$significantly decrease (in raw value, due to its negative nature) with the increase of the oil TPC (from $c v$. Arbequina oil $\rightarrow$ blend oil $\rightarrow c v$. Cobrançosa oil), pointing out the low tendency of the oils to undergo oxidation reactions. At this point, it should be noticed that the abovementioned kinetic and thermodynamic parameters $\left(T_{\mathrm{C}}, Q_{10}, E_{a}, A, \Delta \mathrm{H}^{++}\right.$, and $\left.\Delta \mathrm{S}^{++}\right)$did not show a significant statistical difference among $c v$. Cobrançosa and blend oils, which had the two highest levels of TPC, suggesting a possible boundary of the beneficial effect associated to the TPC in which refers to the thermal stability of an olive oil.

The Gibbs free energy of activation $\left(\Delta \mathrm{G}^{++}\right)$at a given temperature was further used to simultaneously evaluate the effect of $\Delta \mathrm{H}^{++}$and $\Delta \mathrm{S}^{++}$on the lipid oxidation rate (Farhoosh and Hoseini-Yazdi, 2014; Heidarpour and Farhoosh, 2018; Mahdavianmehr et al., 2016). Indeed, high $\Delta \mathrm{G}^{++}$values would correspond to lower lipid oxidation reaction rates and so, to a higher oxidative stability of the lipid system. Thus, $\Delta \mathrm{G}^{++}$values were calculated at five temperatures (from 120 to $160{ }^{\circ} \mathrm{C}$ ) using Eq. 10, being the mean values determined shown in Table 2. Although, from a statistical point of view, an increase of the TPC of the olive oil would lead to a significant increase of $\Delta \mathrm{G}^{++}$( $P$-value $<0.0001$, one-way ANOVA), implying a higher resistance to lipid oxidation of the $c v$. Cobrançosa oils (with greater TPC) compared to $c v$. Arbequina oils, it should be remarked that, for each studied temperature, the real rise was lower than $2 \%$. A slightly more pronounced effect could be observed with the increase of the oxidation temperature, for each olive oil class, being observed a rise of $\sim 5 \%$, which could be due to the endothermic nature of the activated complexes formed during the thermal oxidation process of the oils as well as to the lower disorder rate of the reactants in the activated complexes (Farhoosh and Hoseini-Yazdi, 2014; Mahdavianmehr et al., 2016). As well, the $\Delta \mathrm{G}^{++}$values determined in this study (mean values within 130.02-$137.15 \mathrm{~kJ} \mathrm{~mol}^{-1}$ ) are of the same order of magnitude of those previously reported by Farhoosh and Hoseini-Yazdi (2014) for different olive oils $\left(120-130 \mathrm{~kJ} \mathrm{~mol}^{-1}\right)$ and slightly greater than those found by Mahdavianmehr et al. (2016) for pure triacylglycerols obtained from olive oils (112. $92-120.05 \mathrm{~kJ} \mathrm{~mol}^{-1}$ ). In conclusion, the positive values found clearly pointed out the nonspontaneous nature of the lipid oxidation reaction. Lastly, it should also be remarked that, based on the preliminary data obtained, Portuguese $c v$. Cobrançosa olive oils with high TPC and bitter-pungent intensities, had more favorable kinetic-thermodynamic characteristics than oils produced from the worldwide spread Arbequina cultivar, leading the former to more thermally stable oils.

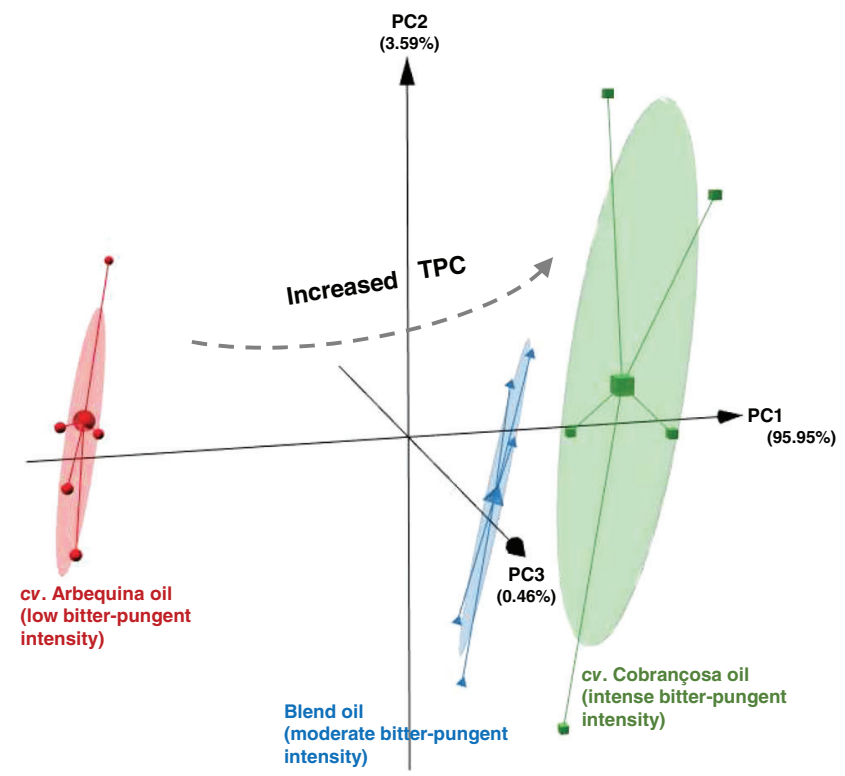

Fig. 2 PCA 3D plot based on a low level of abstraction data fusion approach merging olive oils' kinetic and thermodynamic parameters (temperature coefficient; temperature acceleration factor; frequency factor; activation energy; enthalpy, entropy and free Gibbs energy of activation), with a natural unsupervised EVOO split according to the binomial olive cultivar/TPC: $(\bullet) c v$. Arbequina; (ム) blend; and, (曰) $c v$. Cobrançosa

\section{Kinetic Parameters as Putative Olive Oil Qualitative Classifiers}

As previously discussed, the kinetic/thermodynamic parameters of the olive oils $\left(T_{\mathrm{C}}, Q_{10}, A, E_{\mathrm{a}}, \Delta \mathrm{H}^{++}, \Delta \mathrm{S}^{++}\right.$and $\Delta \mathrm{G}^{++}$) showed a significant dependence on the type of oil under study, being highly influenced by the binomial olive cultivar/TPC (or the related bitter-pungent intensity of the studied oils). Therefore, the use of the kinetic data for classifying the olive oils according to the olive cultivar/TPC was further checked using PCA and a low abstraction level data fusion, approach. The 3D plot of the first three principal components (PC), which accounted for $110 \%$ of the data variability is shown in Fig. 2. The results showed that olive oils were assembled into unsupervised groups according to the increase of the TPC (following the order $c v$. Arbequina oil $\rightarrow$ blend oil $\rightarrow c v$. Cobrançosa oil). In fact, the placement of the unsupervised formed groups along the PC1 strengthened the hypothesis that the kinetic parameters were highly influenced by the olive cultivar/ TPC of the EVOO studied, although other factors should also be considered like the fatty acid profiles, the individual phenolic composition or of other bioactive compounds usually found in olive oils. To further assess which of the kinetic parameters were the most influenced by the olive cultivar/TPC and so, had the most promising discriminative potential, a LDA-SA technique was applied. The 
supervised approach allowed establishing a predictive classification model with two discriminant functions (explaining $100 \%$ of the data variability) based on the $Q_{10}$ and $\Delta \mathrm{G}_{160^{\circ} \mathrm{C}}^{++}$parameters, which were selected by the SA algorithm as the most powerful discrimination variables. The model correctly classified $93 \%$ of the samples for both original data grouped and LOO-CV procedure, being only one $c v$. Cobrançosa oil sample with high TPC (i.e., intense bitter-pungent sensation) misclassified as a blend oil with medium TPC (i.e., moderate bitter-pungent sensation). The LDA-SA approach confirmed the results of the PCA, showing that olive oil kinetic parameters highly depend on the binomial olive cultivar/TPC and thus allowing their use as putative olive oil's fingerprint besides the relevant information regarding the oils oxidative stability and consequently the oils shelf life.

\section{Conclusions}

The Rancimat method was effective for evaluating the kinetic and thermodynamic parameters of olive oils, namely $c v$. Arbequina oil, $c v$. Cobrançosa oil and a blend oil, which had different bitter-pungent intensities and TPC. The binomial olive cultivar/TPC influenced the kinetic-thermodynamic characteristics of the oils, being the lipid oxidation extent less pronounced for $c v$. Cobrançosa oils that had higher TPC and bitter-pungent intensities. The results confirmed that the lipid oxidation was a nonspontaneous process with an endothermic nature with a putative association mechanism. Also, although an Arrhenius behavior could be assumed, a slight nonArrhenius temperature dependence of the reaction rates could be observed, which was more marked for $c v$. Arbequina oils that had lower TPC. Globally, the kinetic-thermodynamic evaluation confirmed that the OS of the oils was affect by the binomial olive cultivar/TPC. Finally, the kinetic-thermodynamic parameters allowed an unsupervised classification of the oils according to olive cultivar/TPC, being the temperature acceleration factor and the Gibbs free energy of activation (at $160{ }^{\circ} \mathrm{C}$ ) identified as the most powerful discriminating parameters. In conclusion, it should be emphasized that for a fully evaluation of the kinetic-thermodynamic behavior of the olive oils, besides the binomial olive cultivar/TPC, the knowledge of the composition in fatty acids and in other bioactive compounds would be of utmost relevance.

Acknowledgments The authors are grateful to the Foundation for Science and Technology (FCT, Portugal) for financial support to CIMO (UIDB/00690/2020) and to CEB (UIDB/04469/2020) units and to BioTecNorte operation (NORTE-01-0145-FEDER-000004) funded by the European Regional Development Fund under the scope of Norte2020-Programa Operacional Regional do Norte). Nuno Rodrigues thanks to National funding by FCT- Foundation for
Science and Technology, P.I., through the institutional scientific employment program-contract.

Conflict of Interest The authors declare that they have no conflict of interest.

\section{References}

Aktar, T., \& Adal, E. (2019) Determining the Arrhenius kinetics of avocado oil: Oxidative stability under rancimat test conditions. Foods, 8:236. https://doi.org/10.3390/foods8070236

Aquilanti, V., Coutinho, N. D., \& Carvalho-Silva, V. H. (2017) Kinetics of low-temperature transitions and a reaction rate theory from non-equilibrium distributions. Philosophical Transactions of the Royal Society A: Mathematical, Physical and Engineering Sciences, 375:20160201. https://doi.org/10.1098/rsta.2016.0201

Aquilanti, V., Mundim, K. C., Elango, M., Kleijn, S., \& Kasai, T. (2010) Temperature dependence of chemical and biophysical rate processes: Phenomenological approach to deviations from Arrhenius law. Chemical Physics Letters, 498:209-213. https://doi.org/ 10.1016/j.cplett.2010.08.035

Borges, T. H., Pereira, J. A., Cabrera-Vique, C., Lara, L., Oliveira, A. F., \& Seiquer, I. (2017a) Characterization of Arbequina virgin olive oils produced in different regions of Brazil and Spain: Physicochemical properties, oxidative stability and fatty acid profile. Food Chemistry, 215:454-462. https://doi.org/10.1016/j. foodchem.2016.07.162

Borges, T. H., Pereira, J. A., Cabrera-Vique, C., \& Seiquer, I. (2017b) Study of the antioxidant potential of Arbequina extra virgin olive oils from Brazil and Spain applying combined models of simulated digestion and cell culture markers. Journal of Functional Foods, 37:209-218. https://doi.org/10.1016/j.jff.2017.07.059

Borges, T. H., Serna, A., López, L. C., Lara, L., Nieto, R., \& Seiquer, I. (2019) Composition and antioxidant properties of spanish extra virgin olive oil regarding cultivar, harvest year and crop stage. Antioxidants, 8:217. https://doi.org/10.3390/antiox8070217

Boskou, D., Blekas, G., \& Tsimidou, M. (2006) Olive oil composition. Champaign, IL: AOCS Press.

Cadima, J., Cerdeira, J. O., \& Minhoto, M. (2004) Computational aspects of algorithms for variable selection in the context of principal components. Computational Statistics \& Data Analysis, 47: 225-236. https://doi.org/10.1016/j.csda.2003.11.001

Capannesi, C., Palchetti, I., Mascini, M., \& Parenti, A. (2000) Electrochemical sensor and biosensor for polyphenols detection in olive oils. Food Chemistry, 71:553-562. https://doi.org/10.1016/S03088146(00)00211-9

Casal, S., Malheiro, R., Sendas, A., Oliveira, B. P. P., \& Pereira, J. A. (2010) Olive oil stability under deep-frying conditions. Food and Chemical Toxicology, 48:2972-2979. https://doi.org/10.1016/j.fct. 2010.07.036

Cicerale, S., Lucas, L., \& Keast, R. (2010) Biological activities of phenolic compounds present in virgin olive oil. International Journal of Molecular Sciences, 11:458-479. https://doi.org/10.3390/ ijms 11020458

Ciemniewska-Żytkiewicz, H., Ratusz, K., Bryś, J., Reder, M., \& Koczon, P. (2014) Determination of the oxidative stability of hazelnut oils by PDSC and Rancimat methods. Journal of Thermal Analysis and Calorimetry, 118:875-881. https://doi.org/10.1007/ s10973-014-3861-9

Commission Delegated Regulation (EU) 2015/1830. (2015) Of 8 July 2015 amending regulation (EEC) no 2568/91 on the characteristics of olive oil and olive-residue oil and on the relevant methods of analysis. Official Journal of the European Union, L266:9-13. 
de Sousa, L. S., Garcia, M. A. S., Santos, E. C. P., do Nascimento Silva, J., de Castro, A. G., de Moura, C. V. R., \& de Moura, E. M. (2019) Study of the kinetic and thermodynamic parameters of the oxidative degradation process of biodiesel by the action of antioxidants using the Rancimat and PetroOXY methods. Fuel, 238: 198-207. https://doi.org/10.1016/j.fuel.2018.10.082

de Man, J. M., Tie, F., \& de Man, L. (1987) Formation of short chain volatile organic acids in the automated AOM method. Journal of the American Oil Chemists' Society, 64:993-996. https://doi.org/ 10.1007/BF02542435

Elhussein, E., Bilgin, M., \& Şahin, S. (2018) Oxidative stability of sesame oil extracted from the seeds with different origins: Kinetic and thermodynamic studies under accelerated conditions. Journal of Food Process Engineering, 41:e12878. https://doi.org/10.1111/ jfpe. 12878

Esposto, S., Taticchi, A., Di Maio, I., Urbani, S., Veneziani, G., Selvaggini, R., ... Servili, M. (2015) Effect of an olive phenolic extract on the quality of vegetable oils during frying. Food Chemistry, 176:184-192. https://doi.org/10.1016/j.foodchem.2014.12.036

Farhoosh, R., \& Hoseini-Yazdi, S.-Z. (2013) Shelf-life prediction of olive oils using empirical models developed at low and high temperatures. Food Chemistry, 141:557-565. https://doi.org/10.1016/j. foodchem.2013.03.024

Farhoosh, R., \& Hoseini-Yazdi, S.-Z. (2014) Evolution of oxidative values during kinetic studies on olive oil oxidation in the Rancimat test. Journal of the American Oil Chemists' Society, 91:281-293. https://doi.org/10.1007/s11746-013-2368-z

Farhoosh, R., Niazmand, R., Rezaei, M., \& Sarabi, M. (2008) Kinetic parameter determination of vegetable oil oxidation under Rancimat test conditions. European Journal of Lipid Science and Technology, 110:587-592. https://doi.org/10.1002/ejlt.200800004

Gharby, S., Harhar, H., Mamouni, R., Matthaüs, B., Ait Addi, E. H., \& Charrouf, Z. (2016) Chemical characterization and kinetic parameter determination under Rancimat test conditions of four monovarietal virgin olive oils grown in Morocco. $O C L-$ Oilseeds and Fats, Crops and Lipids, 23:A401. https://doi.org/10. 1051/ocl/2016014

Gülmez, Ö., \& Şahin, S. (2019) Evaluation of oxidative stability in hazelnut oil treated with several antioxidants: Kinetics and thermodynamics studies. LWT-Food Science and Technology, 111: 478-483. https://doi.org/10.1016/j.lwt.2019.05.077

Hasenhuettl, G. L., \& Wan, P. J. (1992) Temperature effects on the determination of oxidative stability with the metrohm rancimat. Journal of the American Oil Chemists' Society, 69:525-527. https://doi.org/10.1007/BF02636102

Heidarpour, M., \& Farhoosh, R. (2018) A preliminary Rancimatbased kinetic approach of detecting olive oil adulteration. LWTFood Science and Technology, 90:77-82. https://doi.org/10.1016/j. lwt.2017.12.015

Kowalski, B., Ratusz, K., Kowalska, D., \& Bekas, W. (2004) Determination of the oxidative stability of vegetable oils by differential scanning calorimetry and Rancimat measurements. European Journal of Lipid Science and Technology, 106:165-169. https://doi.org/ 10.1002/ejlt.200300915

Kuhn, M., \& Johnson, K. (2013) Applied predictive modeling. New York, NY: Springer Science Business Media.

Kurtulbaş, E., Bilgin, M., \& Şahin, S. (2018) Assessment of lipid oxidation in cottonseed oil treated with phytonutrients: Kinetic and thermodynamic studies. Industrial Crops and Products, 124: 593-599. https://doi.org/10.1016/j.indcrop.2018.08.039

Machado, M., Machado, N., Gouvinhas, I., Cunha, M., de Almeida, J. M. M. M., \& Barros, A. I. R. N. A. (2015) Quantification of chemical characteristics of olive fruit and oil of $\mathrm{cv}$ Cobrançosa in two ripening stages using MIR spectroscopy and chemometrics. Food Analytical Methods, 8:1490-1498. https://doi. org/10.1007/s12161-014-0017-2
Mahdavianmehr, H., Farhoosh, R., \& Sharif, A. (2016) Thermal antioxidative kinetics of hydroxytyrosol in selected lipid systems of different unsaturation degree. Journal of the American Oil Chemists' Society, 93:1655-1661. https://doi.org/10.1007/s11746-0162910-x

Malvis, A., Šimon, P., Dubaj, T., Sládková, A., Ház, A., Jablonsky, M., ... Šurina, I. (2019) Determination of the thermal oxidation stability and the kinetic parameters of commercial extra virgin olive oils from different varieties. Journal of Chemistry, 2019:4567973. https://doi.org/10.1155/2019/4567973

Mateos, R., Uceda, M., Aguilera, M. P., Escuderos, M. E., \& Maza, G. B. (2006) Relationship of Rancimat method values at varying temperatures for virgin olive oils. European Food Research and Technology, 223:246-252. https://doi.org/10.1007/s00217005-0185-9

Morsy, M. K., Morsy, O. M., Elbarbary, H. A., \& Saad, M. A. (2019) Enhancing of oxidative stability and quality attributes of olive oil using spirulina (Arthrospira platensis) nanoparticles. LWT_Food Science and Technology, 101:444-455. https://doi.org/10.1016/j. lwt.2018.11.056

Mousavi, S. R. J., \& Niazmand, R. (2017) Fatty acids composition and oxidation kinetic parameters of purslane (Portulaca oleracea) seed oil. Agricultural Research, 6:421-426. https://doi.org/10. 1007/s40003-017-0271-9

Neves, M., Miguel, M., Pedro, L., Barroso, J., Figueiredo, A., Martins, D., \& Dandlen, S. (2011) Variability of olive oil cultivar on stability during storage. Acta Alimentaria, 40:436-448. https:// doi.org/10.1556/AAlim.40.2011.4.3

Ostrowska-Ligeza, E., Bekas, W., Kowalska, D., Lobacz, M., Wroniak, M., \& Kowalski, B. (2010) Kinetics of commercial olive oil oxidation: Dynamic differential scanning calorimetry and Rancimat studies. European Journal of Lipid Science and Technology, 112:268-274. https://doi.org/10.1002/ejlt.200900064

Peres, F., Martins, L. L., Mourato, M., Vitorino, C., Antunes, P., \& Ferreira-Dias, S. (2016a) Phenolic compounds of 'Galega Vulgar' and 'Cobrançosa' olive oils along early ripening stages. Food Chemistry, 211:51-58. https://doi.org/10.1016/j.foodchem.2016. 05.022

Peres, F., Martins, L. L., Mourato, M., Vitorino, C., \& FerreiraDias, S. (2016b) Bioactive compounds of Portuguese virgin olive oils discriminate cultivar and ripening stage. Journal of the American Oil Chemists' Society, 93:1137-1147. https://doi.org/10.1007/ s11746-016-2848-z

Ratusz, K., Popis, E., Ciemniewska-Żytkiewicz, H., \& Wroniak, M. (2016) Oxidative stability of camelina (Camelina sativa L.) oil using pressure differential scanning calorimetry and Rancimat method. Journal of Thermal Analysis and Calorimetry, 126: 343-351. https://doi.org/10.1007/s10973-016-5642-0

Rodrigues, N., Casal, S., Peres, A. M., Baptista, P., Bento, A., Martín, H., ... Pereira, J. A. (2018) Effect of olive trees density on the quality and composition of olive oil from cv. Arbequina. Scientia Horticulturae, 238:222-233. https://doi.org/10.1016/j. scienta.2018.04.059

Rodrigues, N., Dias, L. G., Veloso, A. C. A., Pereira, J. A., \& Peres, A. M. (2016) Evaluation of extra-virgin olive oils shelf life using an electronic tongue-chemometric approach. European Food Research and Technology, 243:597-607. https://doi.org/10.1007/ s00217-016-2773-2

Romagnoli, É. S., Borsato, D., Silva, L. R. C., Chendynski, L. T., Angilelli, K. G., \& Canesin, E. A. (2018) Kinetic parameters of the oxidation reaction of commercial biodiesel with natural antioxidant additives. Industrial Crops and Products, 125:59-64. https://doi. org/10.1016/j.indcrop.2018.08.077

Sacchi, R., Medaglia, D. D., Paduano, A., Caporaso, N., \& Genovese, A. (2017) Characterisation of lemon-flavoured olive 
oils. LWT_Food Science and Technology, 79:326-332. https://doi. org/10.1016/j.lwt.2017.01.025

Silva, V. H. C., Aquilanti, V., De Oliveira, H. C. B., \& Mundim, K. C. (2013) Uniform description of non-Arrhenius temperature dependence of reaction rates, and a heuristic criterion for quantum tunneling vs classical non-extensive distribution. Chemical Physics Letters, 590:201-207. https://doi.org/10.1016/j.cplett. 2013.10.051

Sonkamble, A. A., Sonsale, R. P., Kanshette, M. S., Kabara, K. B., Wananje, K. H., Kumbharkhane, A. C., \& Sarode, A. V. (2017) Relaxation dynamics and thermophysical properties of vegetable oils using time-domain reflectometry. European Biophysics Journal, 46:283-291. https://doi.org/10.1007/s00249-016-1165-7

Sousa, A., Casal, S., Malheiro, R., Lamas, H., Bento, A., \& Pereira, J. A. (2015) Aromatized olive oils: Influence of flavouring in quality, composition, stability, antioxidants, and antiradical potential. LWT_Food Science and Technology, 60:22-28. https:// doi.org/10.1016/j.lwt.2014.08.026

Symoniuk, E., Ratusz, K., \& Krygier, K. (2016) Comparison of the oxidative stability of linseed (Linum usitatissimum L.) oil by pressure differential scanning calorimetry and Rancimat measurements. Journal of Food Science and Technology, 53:3986-3995. https:// doi.org/10.1007/s13197-016-2398-2
Symoniuk, E., Ratusz, K., \& Krygier, K. (2017) Comparison of the oxidative stability of cold-pressed rapeseed oil using pressure differential scanning calorimetry and Rancimat methods. European Journal of Lipid Science and Technology, 119:1600182. https://doi. org/10.1002/ejlt.201600182

Symoniuk, E., Ratusz, K., Ostrowska-Ligęza, E., \& Krygier, K. (2018) Impact of selected chemical characteristics of cold-pressed oils on their oxidative stability determined using the Rancimat and pressure differential scanning calorimetry method. Food Analytical Methods, 11:1095-1104. https://doi.org/10.1007/s12161-0171081-1

Trapani, S., Guerrini, L., Masella, P., Parenti, A., Canuti, V., Picchi, M., ... Zanoni, B. (2017) A kinetic approach to predict the potential effect of malaxation time-temperature conditions on extra virgin olive oil extraction yield. Journal of Food Engineering, 195: 182-190. https://doi.org/10.1016/j.jfoodeng.2016.09.032

Venables, W. N., \& Ripley, B. D. (2002) Modern applied statistics with $S$ (statistics and computing) (4th ed.). New York, NY: Springer.

Yang, K.-M., Hsu, F.-L., Chen, C.-W., Hsu, C.-L., \& Cheng, M.-C. (2018) Quality characterization and oxidative stability of camellia seed oils produced with different roasting temperatures. Journal of Oleo Science, 67:389-396. https://doi.org/10.5650/jos. ess 17190 